\title{
After the AUGUSTUS Trial, Should Apixaban Be the Only Direct Oral Anticoagulant to Be Used in Triple Therapy in Atrial Fibrillation Patients Undergoing Percutaneous Coronary Intervention?
}

\author{
Andrea Rubboli ${ }^{1}$ - Matteo Lisi ${ }^{1}$ \\ Published online: 10 May 2019 \\ (C) Springer Science+Business Media, LLC, part of Springer Nature 2019
}

In patients with atrial fibrillation (AF) undergoing percutaneous coronary intervention with stent (PCI), prospective, randomized evidence on the combination of a direct oral anticoagulant (DOAC) with the single antiplatelet agent clopidogrel (so-called double therapy) is [1-3], or soon will be [4], available for all four agents dabigatran, rivaroxaban, apixaban, and edoxaban [4]. Apixaban is currently the only DOAC being tested in combination with dual antiplatelet therapy (DAPT) of aspirin and clopidogrel (so-called triple therapy) in $\mathrm{AF}$ patients undergoing PCI [3]. Should therefore apixaban be the only DOAC to be used in triple therapy whenever this regimen is selected, and even when at the time of PCI the patient was in chronic oral anticoagulation (OAC) with another DOAC?

According to the recent 2018 joint European consensus document [5], the minimum duration of triple therapy following PCI in AF patients can be limited to 1 month (and even less according to other expert groups) [6, 7]. The scenario that can then possibly arise is that of a patient with AF on chronic OAC with dabigatran, rivaroxaban, or edoxaban being referred for PCI and switched to apixaban after triple therapy has been chosen as the initial antithrombotic regimen (Fig. 1). Once triple

Andrea Rubboli

andrea.rubboli@auslromagna.it

1 Department of Cardiovascular Diseases - AUSL Romagna, Division of Cardiology, Ospedale S. Maria delle Croci, Viale Randi 5, 48121 Ravenna, Italy therapy has been started and switching to apixaban carried out, such combination should be continued for (at most) 1 month, at the end of which, when aspirin is stopped and only clopidogrel is continued for the next 6-12 months, consideration should be given on whether or not reverse switch from apixaban to the initial DAOC for which, whichever it is, prospective, randomized evidence in double combination is, or will soon be, available [1-4], should be performed (Fig. 1). And even if switching from apixaban back to the initial DOAC is not performed at the end of the first month (or less) of triple therapy, and double therapy with apixaban and clopidogrel is continued for the next 6-12 months, at the end of these, when clopidogrel is interrupted and OAC monotherapy continued for life [5-7], the issue arises again.

Because the four DOACs have each their own peculiarities, so that they should not be considered interchangeable (in the persistent lack of direct comparison data), and that their superior safety on bleeding events compared to warfarin appears to be a class effect [8], likely also in combination with antiplatelet therapy, the ongoing DOAC at the time of PCI should probably be continued for the next days or weeks of triple therapy (when selected). Unless specific considerations arise, the DOAC that has been previously judged as optimal for the whole patient's life should not routinely be changed only because DAPT should be given in combination for few days or weeks. On the contrary, should AF arise following PCI and triple therapy is selected as the initial antithrombotic therapy, apixaban should likely be the DOAC of choice given its exclusive data in combination with DAPT. 
Fig. 1 Possible scenario after choosing triple therapy with apixaban in an AF patient on chronic dabigatran/rivaroxaban/ edoxaban undergoing PCI. AF atrial fibrillation, $\mathrm{PCI}$ percutaneous coronary intervention

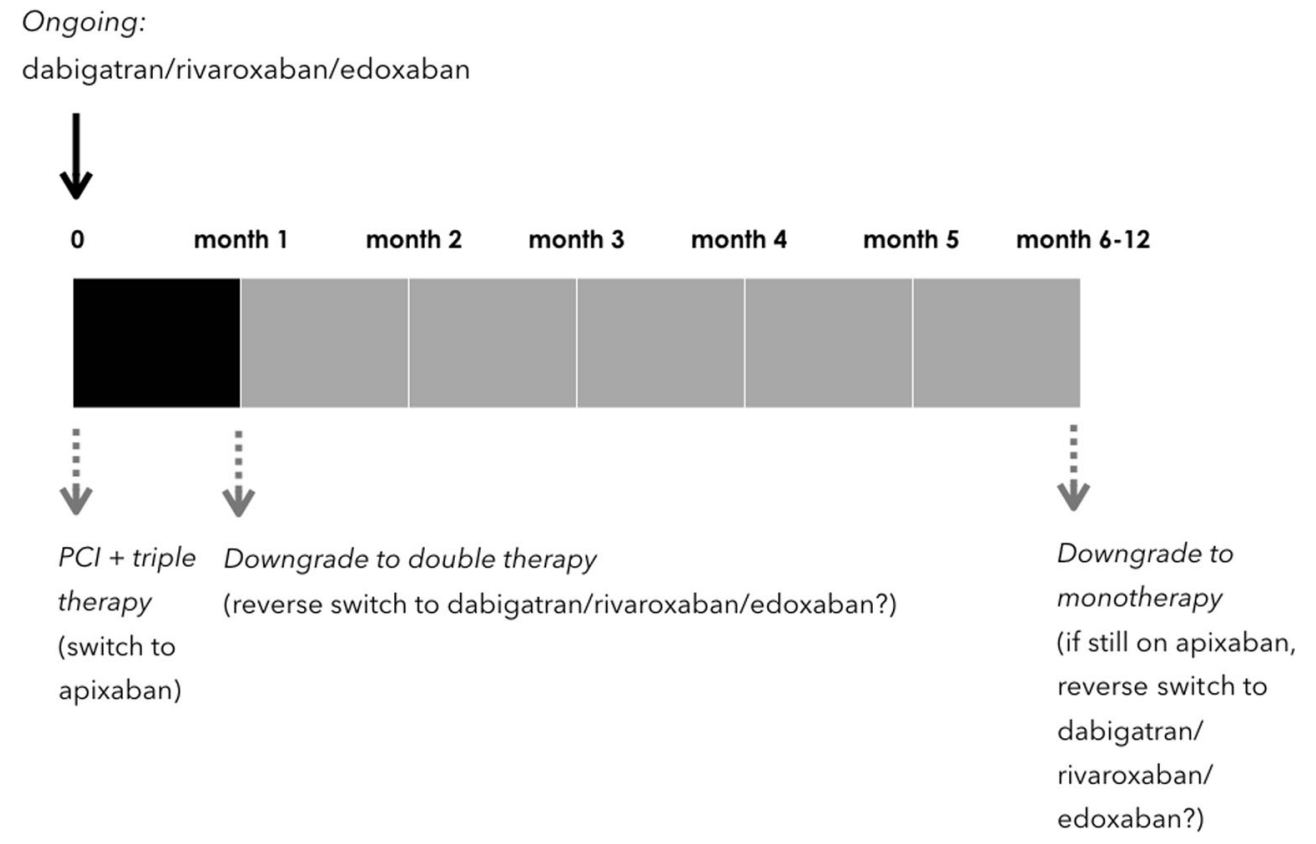

\section{References}

1. Gibson CM, Mehran R, Bode C, Halperin J, Verheugt FW, Wildgoose $\mathrm{P}$, et al. Prevention of bleeding in patients with atrial fibrillation undergoing PCI. N Engl J Med. 2016;375:2423-34.

2. Cannon CP, Bhatt DL, Oldgren J, Lip GYH, Ellis SG, Kimura T, et al. RE-DUAL PCI steering committee and investigators. Dual antithrombotic therapy with dabigatran after PCI in atrial fibrillation. N Engl J Med. 2017;377:1513-24.

3. Lopes RD, Heizer G, Aronson R, Vora AN, Massaro T, Mehran $\mathrm{R}$, et al. AUGUSTUS Investigators. Antithrombotic therapy after acute coronary syndrome or PCI in atrial fibrillation. N Engl J Med. 2019;380:1509-24.

4. Vranckx P, Lewalter T, Valgimigli M, Tijssen JG, Reimitz PE, Eckardt L, et al. Evaluation of the safety and efficacy of an edoxaban-based antithrombotic regimen in patients with atrial fibrillation following successful percutaneous coronary intervention (PCI) with stent placement: rationale and design of the ENTRUST-AF PCI trial. Am Heart J. 2018;196:105-12.

5. Lip GYH, Collet JP, Haude M, Byrne R, Chung EH, Fauchier L, et al. ESC Scientific Document Group. 2018 Joint European consensus document on the management of antithrombotic therapy in atrial fibrillation patients presenting with acute coronary syndrome and/or undergoing percutaneous cardiovascular inter- ventions: a joint consensus document of the European Heart Rhythm Association (EHRA), European Society of Cardiology Working Group on Thrombosis, European Association of Percutaneous Cardiovascular Interventions (EAPCI), and European Association of Acute Cardiac Care (ACCA) endorsed by the Heart Rhythm Society (HRS), Asia-Pacific Heart Rhythm Society (APHRS), Latin America Heart Rhythm Society (LAHRS), and Cardiac Arrhythmia Society of Southern Africa (CASSA). Europace. 2019;21:192-3

6. Steffel J, Verhamme P, Potpara TS, Albaladejo P, Antz M, Desteghe L, et al. The 2018 European Heart Rhythm Association Practical Guide on the use of non-vitamin $\mathrm{K}$ antagonist oral anticoagulants in patients with atrial fibrillation: executive summary. Europace. 2018;20:1231-42.

7. Angiolillo DJ, Goodman SG, Bhatt DL, Eikelboom JW, Price MJ, Moliterno DJ, et al. Antithrombotic therapy in patients with atrial fibrillation treated with oral anticoagulation undergoing percutaneous coronary intervention. Circulation. 2018;138:527-36.

8. Ruff CT, Giugliano RP, Braunwald E, Hoffman EB, Deenadayalu N, Ezekowitz MD, et al. Comparison of the efficacy and safety of new oral anticoagulants with warfarin in patients with atrial fibrillation: a meta-analysis of randomised trials. Lancet. 2014;383:955-62.

Publisher's Note Springer Nature remains neutral with regard to jurisdictional claims in published maps and institutional affiliations. 